\title{
Multi-cluster technology learning in TIMES: a transport sector case study with TIAM-UCL
}

\author{
Gabrial Anandarajah and Will McDowall
}

\begin{abstract}
The costs of technologies often fall over time due to a range of processes including learning-by-doing. This is a well-characterized concept in the economics of innovation, in which learning about a particular technology, and hence cost reduction, is related to cumulative investments in that technology. This chapter provides a case study applying technology learning endogenously in a TIMES model. It describes many of the key challenges in modelling technology learning endogenously, both in terms of the interpretation and policy relevance of the results, and in terms of methodological challenges. The chapter then presents a case study, exploring a multi-cluster learning approach where many key technologies (fuel cells, automotive batteries, and electric drivetrains) are shared across a set of transport modes (cars, buses and LGVs) and technologies (hybrid and plugin hybrid fuel cell vehicles, battery electric vehicles, hybrid and plug-in hybrid petrol and diesel vehicles). The multi-region TIAM-UCL Global energy system model has been used to model the multi-cluster approach. The analysis is used to explore the competitive and/or complementary relationship between hydrogen and electricity as low-carbon transport fuels.
\end{abstract}

\section{Introduction}

Energy system models inform policymakers about the potential importance of particular technologies by examining whether their presence or absence (at a given cost/performance) influences the overall costs of decarbonisation. In examining the potential of new technologies, technology-rich models like TIMES and MARKAL take one of three approaches, which can be varied with different model runs or scenarios, for the capital cost of a technology:

1. Assume no technological change to examine whether, with stock turnovers, current technologies are sufficient to meet energy system goals.

2. Use exogenous forecasts of technological development, drawn from a range of sources. This is the approach that is typically taken with MARKAL and TIMES model.

3. Endogenise technological change into the model structure (by implementing "Endogenous Technology Learning" or ETL).

Most bottom-up energy system models adopt the second approach, using exogenous forecasts of technological development to represent technology improvements. These forecasts come from diverse sources, for which underlying assump-

\footnotetext{
Gabrial Anandarajah (corresponding author), UCL Energy Institute, University College London, United Kingdom, g.anandarajah@ucl.ac.uk

Will McDowall, University College London, United Kingdom, w.mcdowall@ucl.ac.uk
} 
tions are not always clear. Typically, it is recognized that while significant cost reduction is possible as a result of research and development (R\&D) before a technology enters markets, there is further cost reduction after market introduction, as a result of learning-by-doing, economies of scale, continued R\&D and other factors such as maturing supply chains. Some technological forecasts are produced on the basis of learning curve studies that posit a particular level of deployment of the technology. This can lead to several problems:

- First, the models' technology choice is resting on inputs that already assume the success of particular technologies. If the analyst is interested in optimal technology portfolios, this is clearly problematic: the input data already incorporates assumptions about which technologies will be most widely deployed.

- Second, exogenous technology learning allows the energy system to get the benefits of learning for free. There is no need to deploy expensive first-of-akind technologies, because in later years the costs will have fallen. It is possible that this appears to implicitly advocate a wait-and-see mode of technology deployment (it is not cost effective yet, so it should not be deployed yet); and it understates the total investment requirements and costs of decarbonisation, since learning costs are ignored. This has been described as 'learning without doing' (Seebregts et al. 1999).

Endogenous technology learning thus improves the internal consistency of the models (Grubb et al. 2002), and can be more appropriate for analysis attempting to gauge the relative importance of different technologies. Multi-cluster ETLenabled models also allow insights into technology dynamics, which may suggest that technologies are worth supporting even if they are not in themselves the leastcost option, because they support learning that enables other lower cost solutions ${ }^{1}$.

This Chapter provides a case study applying technology learning endogenously in TIMES model. It applies a multi-cluster approach where many key technologies (fuel cells, automotive batteries, and electric drivetrains) are shared across a set of transport modes (cars, buses and LGVs) and technologies (hybrid and plug-in hybrid fuel cell vehicles, battery electric vehicles, hybrid and plug-in hybrid petrol and diesel vehicles). The analysis is used to explore the synergies and interactions between key component technologies, and the competitive and/or complementary relationship between hydrogen and electricity as low-carbon transport fuels.

\section{Background: Modelling technology learning and the expe- rience curve}

\footnotetext{
${ }^{1}$ e.g. fuel cell buses may not themselves be the least-cost bus technology in a carbon constrained future; but they may 'earn' their position in a least-cost solution if their deployment results in learning that can be applied to cars
} 
The relationship between cumulative deployment and capital cost-described as the "learning curve"-is a well-characterized concept in the economics of innovation. Learning curves have been determined empirically for a wide range of energy technologies (McDonald and Schrattenholzer 2001)[3]. The most common formulation of the learning curve is described by Equation (1) below:

$$
C_{t}=C_{0} *\left(Q_{t} / Q_{0}\right)^{-b}
$$

Equation (1)

Where $C_{0}$ and $Q_{0}$ are the initial capital cost and initial installed capacity respectively, while $\mathrm{C}_{\mathrm{t}}$ and $Q_{t}$ are the capital cost and cumulative installed capacity respectively at time t. The parameter $b$ is not intuitively easy to grasp, so is usually expressed as the progress ratio $\left(P R=2^{-\mathrm{b}}\right)$ or the learning rate $(L R=1-P R)$. The learning rate is the cost reduction achieved for a doubling of cumulative capacity, and is typically around $15-20 \%$ for new energy technologies (Gritsevskyi and Nakićenovic 2000; Seebregts et al. 1998).

The learning curve equation, based on cumulative capacity, is an intuitive and analytically tractable account of how deployment relates to technological change. As a result, it has become the most widespread approach to implementing technology learning endogenously within energy-economy models. However, a growing literature-from both quantitative analysts and more qualitative 'innovation studies' scholars (Winskel et al. 2013) highlights the complexities that such a basic formulation overlooks. Perhaps unsurprisingly, representing technology dynamics effectively in energy systems and integrated assessment models is recognised as one of the great challenges for the field (Grubb et al. 2002). Here, we highlight three key methodological challenges and issues in modelling ETL, and the ways in which previous analysis has addressed them.

First, empirically derived learning curves capture changes that are both time dependent (typically thought to reflect learning 'by research'), and scale dependent (including returns to scale, and maturation of supply chains). For this reason, some scholars prefer the term 'experience curve'. Disentangling those different factors is not always straightforward, and the estimation of true 'learning by doing' can thus be challenging. Other factors come into play too - commodity costs, supply-chain bottlenecks, and the processes of 'forgetting' (described by economists as depreciation of knowledge stocks) that can occur when an industry experiences pauses or set-backs, as has occurred with the nuclear industry in many countries. The wider innovation literature highlights the existence of regulatory and wider socio-technical processes (such as socially conferred 'legitimacy' and the establishment of political lobbying power) that also go hand in hand with successful deployment, and help to reinforce allocation of R\&D budgets and reduction in regulatory and transaction costs (Bergek et al. 2008). Some authors have suggested that the specification of future learning rates in models should therefore be dependent on the policy scenario (Winskel et al. 2014). 
Some authors have attempted to disaggregate these diverse learning and other effects. For example, the separate processes of learning-by-doing and learning-byresearch have been modelled by adopting a 'two-factor' learning curve, in which both cumulative capacity, and some measure of the R\&D knowledge stock, influence rates of learning (e.g. Totschnig and Keppo 2007, Criqui et al 2014). Others have developed three-factor or multi-factor models (Yeh and Rubin 2012). However, such approaches add analytic complexity, and may not be appropriate for a large, technology rich model. In any case, an innovation system perspective suggests that it is rare that technologies are fostered solely through R\&D or solely through deployment with no accompanying R\&D. It seems possible that a single learning curve, though undoubtedly a simplification, may be well placed to represent aggregate capacity-cost relationships that emerge from a wide range of processes, including both true 'learning' and other correlated processes. A similar point is made by Watanabe et al. (2000) and Kahouli-Brahmi (2008), and a good discussion of the issues is provided by Yeh and Rubin (2012). An alternative to two-factor or multi-factor learning is to model exogenous learning as a function of time in addition to learning-by-doing.

Second, technologies are often closely related, and cost reductions in one application often leads to cost reductions for a related technology in a different application, even where slightly different characteristics are required. In modelling ETL, it is possible to create 'clusters' of closely-related technologies, which share learning, to account for this effect. Examples of cluster-based learning include Totschnig and Keppo (2007), who assessed clusters around several key technologies for cars (fuel cells, hydrogen tanks, hybrid systems, and onboard fuel reformers); and Gritsevski and Nakicenovic (2000), who modelled ETL for fuel cells, with full spill-overs between different types of fuel cell for cars (e.g. running on hydrogen vs. on methanol), and partial spill-overs between automotive and stationary fuel cells. Krzyzanowski et al. (2004) explored clusters in which learning in hybrid drive trains is shared between light trucks and cars, and it appears that Krzyzanowski et al. (2008) explored cluster learning in which fuel cell learning was shared between buses and cars, but this is not made explicitly clear in the paper. Gül et al. (2009) applied learning to clusters of hydrogen and electricity production technologies, but the representation of transport technologies does not use a cluster approach, and so does not enable spill-overs between e.g. fuel cell cars and battery electric light goods vehicles.

The degree of spill-over between particular technologies is an important assumption in such analysis, but it is not clear that such relationships can be forecasted with any accuracy. Past practice has tended to make assumptions about the degree of relatedness and spill-over, largely on the basis of modeller judgement rather than empirical evidence. Furthermore, it is not necessarily straightforward to define the level of aggregation at which to study (and model) the experience curve. Components (such as wind turbine blades or nacelles) may develop at different rates from the aggregate wind turbine. 
A third methodological challenge relates to the perfect foresight nature of bottom-up energy system models such as MARKAL/TIMES. Many earlier studies applying ETL in MARKAL/TIMES or other bottom-up optimization models (e.g. Mattsson and Wene, 1997; Seebregts et al. 1998; Feber et al 2003) found that the model tends to deploy the 'learning technology' very rapidly and to the greatest extent possible - or not at all. In terms of interpretation, this raises questions about the feasibility of very rapid transitions from one technology to another, as well as questions about the relationship between deployment speed and learning rate. An observation from the rapid roll-out of flue-gas desulphurisation in Germany during the 1980s was that simultaneous deployment across a large number of power stations inhibited effective learning because the same mistakes were being made at the same time (Eames 2000). There was no time to learn from one installation and apply those lessons to the next, since they were not occurring sequentially. The implications of this observation for system models is that the relationship between learning rates and deployment rates (and rate constraints) should be considered, at least in the interpretation of results if not endogenously within the model.

The immediately-or-never pattern of deployment of a learning technology within an ETL model has led some authors to advocate caution in modelling ETL: if the resulting model dynamics are simply the result of exogenous rate constraints and upper bounds, then there may be few additional insights derived from the considerable effort required to endogenise learning in the model (Loulou et al. 2005). However, the approach presented in the case study in this chapter appears to reduce the problem of immediately-or-never deployment in an ETL model. This case study applies multiple clusters in which key vehicle components (automotive batteries, fuel cells, and electric drivetrains) undergo learning that is then combined within and shared across vehicle modes (buses, HGVs, cars). As the analysis shows, the model does not show the immediately-or-never behavior typical to previous work with ETL in energy system models.

\section{Endogenous Technology Learning in TIMES}

To represent learning-by-doing in TIMES, the investment cost (INVCOST) of the learning technology will decrease with the cumulative investment of the learning technology. The investment cost of the learning technology becomes a variable investment cost. This is represented by equation 2 .

$$
I N V C O S T=a C_{t}^{-b}
$$

$$
\text { Equation (2) }
$$

Where, $a$ is initial investment cost, $C$ is cumulative investment and $b$ represents learning. Since the relationship between the investment cost and learning rate is non-linear (Equation 1), the TIMES model's objective function will yield a nonlinear expression, which as a linear programming model it is unable to solve. To 
avoid a non-linear relationship, the investment cost in the objective function will be represented by piecewise linear approximation of total investment cost $(T C t)$ as shown in Figure 1. The cumulative learning curve is approximated by linear segments and binary variables are used-leading to mixed integer programming, which increases computing time.

Learning in one technology often enables cost reductions in closely related technologies. To account for this effect, a cluster approach can be used in TIMES, in which a group of technologies sharing a common component- the 'key technology'-learn together. The technologies constituting a cluster are related by multiple links that contribute to magnify their economic, social and environmental impacts (Grübler et al. 1999). These multiple relations ensure that progress in one technology contributes, directly or indirectly, to progress for other members of the cluster, as it helps to reinforce their own position in the marketplace.

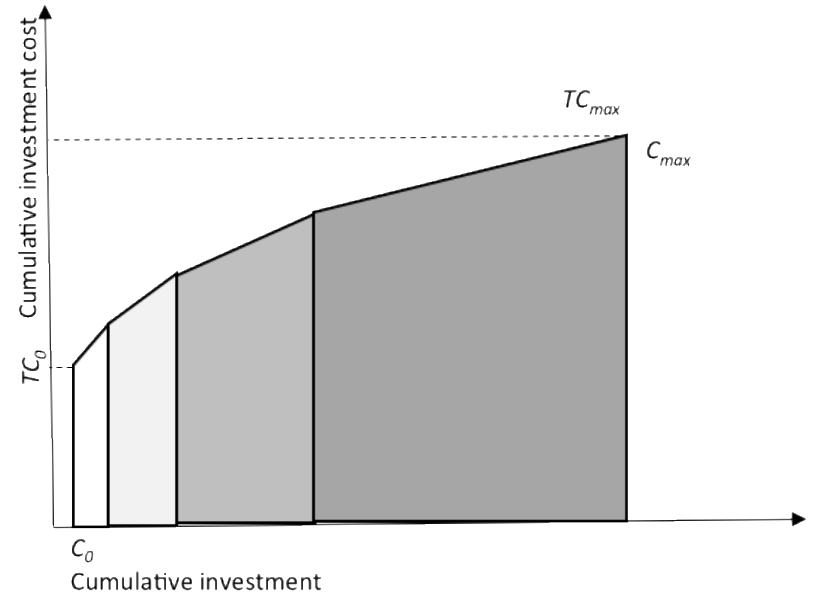

Fig. 1. Segment approximation of the cumulative cost curve

In TIMES, it is possible to apply learning for a single technology at a regional level or global level. When learning is global, deployment yields cost reductions for users of the technology worldwide regardless of which region has deployed the technology — learning is said to spill over globally.

For each learning technology, the user provides:

- The progress ratio $p r$ ( $p r=2^{-b} ; 1-p r$ (learning rate) is the cost reduction incurred when cumulative investment is doubled);

- One initial point on the learning curve, denoted $\left(C_{0}, T C_{0}\right)$ and floor cost;

- The maximum allowed cumulative investment $C_{\max }$ (from which the maximum total investment cost $T C_{\max }$ may be inferred);

- The number $N$ of segments for approximating the cumulative learning curve over the $\left(C_{0}, C_{\max }\right)$ interval (note that $N$ may be different for different technologies). 
As noted above, many previous applications of ETL within MARKAL/TIMES models have observed that the model tends to select learning technologies, and invest massively in early periods in these technologies in order to lower future cost. The resulting unrealistically rapid deployment can be prevented by additional constraints (build rate). Results are then conditioned by the exogenous upper bound. The discount rate provides an incentive for postponing investments. Investing early allows the unit investment cost to drop immediately, and thus allows much cheaper investments in the learning technologies in the current and all future periods. The resulting dynamics depend on the learning rate and the discount rate.

\section{Case Study}

\subsection{Introduction}

Both hydrogen and electricity have been widely discussed as possible fuels for decarbonising road transport, as long as hydrogen and/or electricity is produced in a sustainable manner. Yet deployment of such vehicles is currently limited, as battery electric and fuel cell technologies are too expensive to compete technoeconomically with internal combustion vehicles using fossil fuels. This case study, which draws on Anandarajah et al. (2013), analyses the long-term role of hydrogen and electricity in facilitating decarbonisation of the global transport sector by implementing global learning endogenously in the TIAM-UCL multi-regional global energy system model. The 16-region TIAM-UCL model has been developed at UCL through the UK Energy Research Centre (UKERC) by breaking out the UK from the Western Europe Region in the 15- Region ETSAP-TIAM² model, which is the global multiregional incarnation of the TIMES model generator (Loulou et al. 2005; Loulou and Labriet 2007).

\subsection{Technology learning}

The cluster approach adopted in this paper uses single factor learning, where a group of technologies sharing a common component - the 'key technology' learn together. For example, fuel cells are an example of a key component technology, and members of the corresponding cluster of 'shell' technologies in which the component is used are hybrid- and plug-in hybrid- fuel cell vehicles both in cars and light goods vehicles (LGVs) as well as in buses. Three key component technologies undergo learning in the model, and are thus explicitly represented in the model as technologies in their own right, in addition to the vehicle 'shell' systems in which they are deployed (Figure 2):

- Fuel cell systems $(\$ / \mathrm{kW})$

- Electric drivetrains $(\$ / \mathrm{kW})$

\footnotetext{
${ }^{2}$ ETSAP-TIAM, originally developed by KanLo (www.kanors.com/DCM/TIAM)
} 
- Automotive battery systems $(\$ / \mathrm{kWh})$

Only investment costs undergo learning. As a result, the component technologies in the model only carry investment costs. Efficiency and O\&M costs are attributes of the vehicles (shell) themselves. Each of these component technologies is embedded in vehicles that use them. For example, a hybrid hydrogen fuel cell vehicle uses electric drivetrain, battery, and a fuel cell system. A plug-in hybrid petrol car, in contrast, uses an electric drivetrain and battery but no fuel cell. Table 1 shows the vehicle types, the acronyms used to describe them in this paper, the fuels they use, and which of the component 'key technologies' they use. Data are not shown in the table, for brevity, since the capacity of each key technology differs depending on whether the vehicle type is deployed as a car, bus or LGV. Data can be found in McDowall (2012).

Table 1. Vehicle types in the model. All vehicle types are available as cars and light goods vehicles (LGVs), only those marked with an asterisk are available as buses.

\begin{tabular}{|c|c|c|c|c|c|}
\hline \multirow[b]{2}{*}{ Vehicle type } & \multirow[b]{2}{*}{ Acronym } & \multirow[b]{2}{*}{ Fuels used } & \multicolumn{3}{|c|}{ Key technologies } \\
\hline & & & Battery & $\begin{array}{l}\text { Electric } \\
\text { Drive }\end{array}$ & $\begin{array}{l}\text { Fuel } \\
\text { cell }\end{array}$ \\
\hline Petrol vehicle & Petrol ICE & Petrol or ethanol & $x$ & $x$ & $x$ \\
\hline Diesel vehicle* & Diesel ICE & Diesel or biodiesel & $x$ & $x$ & $x$ \\
\hline $\begin{array}{l}\text { Petrol hybrid } \\
\text { vehicle }\end{array}$ & Petrol HEV & Petrol or ethanol & $\checkmark$ & $\checkmark$ & $x$ \\
\hline $\begin{array}{l}\text { Diesel hybrid } \\
\text { vehicle* }\end{array}$ & Diesel HEV & Diesel or biodiesel & $\checkmark$ & $\checkmark$ & $x$ \\
\hline $\begin{array}{l}\text { Petrol plug-in } \\
\text { hybrid vehicle }\end{array}$ & Petrol PHEV & $\begin{array}{l}\text { Petrol or ethanol } \\
\text { and electricity }\end{array}$ & $\checkmark$ & $\checkmark$ & $x$ \\
\hline $\begin{array}{l}\text { Diesel plug-in } \\
\text { hybrid vehicle }\end{array}$ & Diesel PHEV & $\begin{array}{l}\text { Diesel or biodiesel } \\
\text { and electricity }\end{array}$ & $\checkmark$ & $\checkmark$ & $x$ \\
\hline Fuel cell vehicle & $\mathrm{FCV}$ & Hydrogen & $x$ & $\checkmark$ & $\checkmark$ \\
\hline $\begin{array}{l}\text { Fuel cell hybrid } \\
\text { vehicle* }\end{array}$ & FCHV & Hydrogen & $\checkmark$ & $\checkmark$ & $\checkmark$ \\
\hline $\begin{array}{l}\text { Fuel cell plug-in } \\
\text { hybrid vehicle }\end{array}$ & FCPHEV & $\begin{array}{l}\text { Hydrogen and elec- } \\
\text { tricity }\end{array}$ & $\checkmark$ & $\checkmark$ & $\checkmark$ \\
\hline $\begin{array}{l}\text { Battery electric } \\
\text { vehicle }\end{array}$ & $\mathrm{BEV}$ & Electricity & $\checkmark$ & $\checkmark$ & $x$ \\
\hline $\begin{array}{l}\text { Natural gas ve- } \\
\text { hicle* }\end{array}$ & $\mathrm{CNG}$ & Natural gas & $x$ & $x$ & $x$ \\
\hline LPG vehicle & LPG & $\begin{array}{l}\text { Liquefied petrole- } \\
\text { um gas }\end{array}$ & $x$ & $x$ & $x$ \\
\hline
\end{tabular}




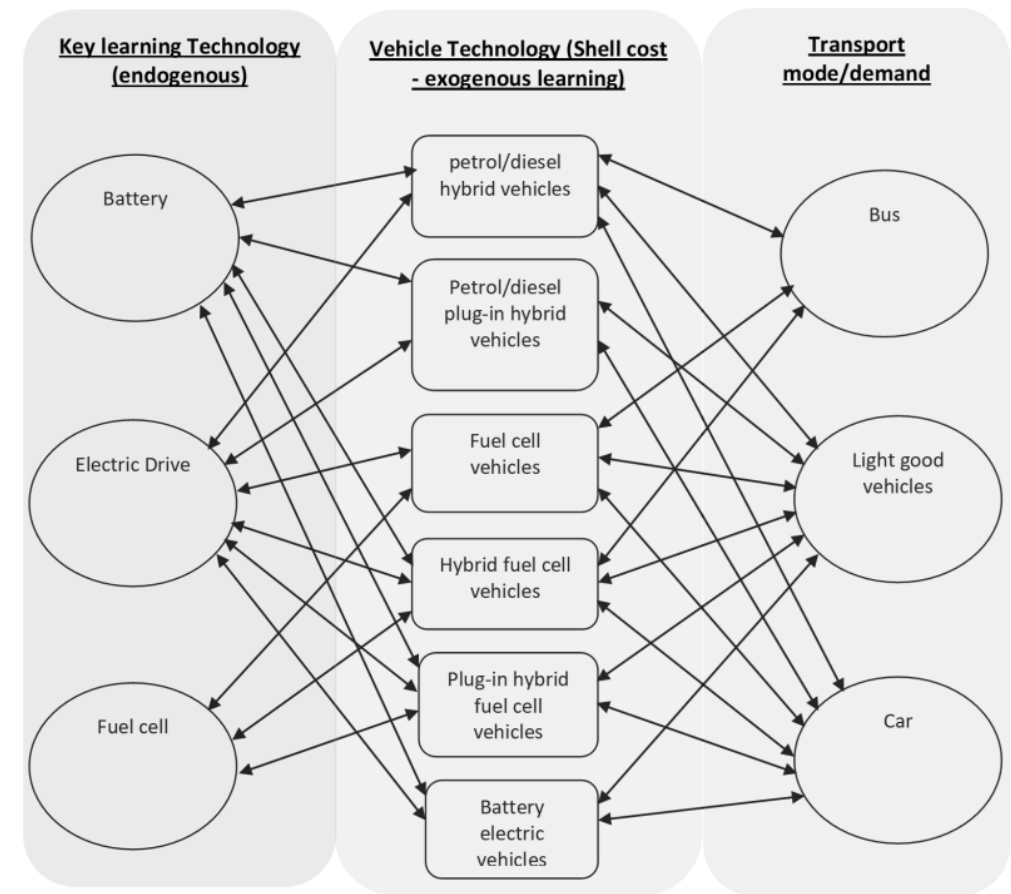

Fig. 2. Multi-cluster learning approach modelled in TIAM-UCL

Learning for a component takes place regardless of the vehicle type in which it is deployed. i.e. cost reductions that arise from deployment of fuel cells in buses also apply to fuel cells for use in cars. Shared learning of this kind is thought realistic by the automotive industry, which sees opportunities for hybrid vehicles to provide a stepping stone into electric vehicles, whether battery powered or fuel cell powered (Lipman and Hwang 2003). Similarly, Zaetta and Madden (2011) suggest that a plausible route for bus fuel cell system development is through shared learning with car fuel cells.

\subsection{Data}

Documentation for TIAM-UCL is available in the website of the UK Energy Research Centre, and data and assumptions for vehicle characteristics and learning technologies are fully documented in McDowall (2012) and McDowall and Dodds (2012). For brevity, only the key technology learning parameters (learning rate, initial cost, initial capacity and floor cost) are presented in Table 2. It is assumed that learning can start from 2015. All costs are in year 2005 US\$. 
Table 2. Data on key learning technologies. Detailed assumptions found in McDowall (2012).

\begin{tabular}{|c|c|c|c|}
\hline & $\begin{array}{l}\text { Fuel cell } \\
\text { system } \\
\$ / \mathrm{kW} \\
\end{array}$ & $\begin{array}{c}\text { Electric } \\
\text { powertrain } \\
\$ / k W \\
\end{array}$ & $\begin{array}{c}\text { Automotive } \\
\text { batteries } \\
\$ / k W h \\
\end{array}$ \\
\hline Initial cost & 883 & 244 & 756 \\
\hline Floor cost & 27 & 24 & 151 \\
\hline \multirow[t]{2}{*}{ Learning rate } & $18 \%$ & $10 \%$ & $7 \%$ \\
\hline & GW & GW & GWh \\
\hline $\begin{array}{l}\text { Initial installed ca- } \\
\text { pacity }\end{array}$ & 1.1 & 250 & 6.5 \\
\hline $\begin{array}{l}\text { Number of dou- } \\
\text { blings of capacity to } \\
\text { reach floor cost }\end{array}$ & 18 & 23 & 23 \\
\hline
\end{tabular}

\section{Scenarios}

Five groups of scenarios have been run in order to examine the role of learning in determining the optimality of electricity and hydrogen in the global road transport sector. All scenarios are greenhouse gas (GHG) reduction scenarios, in which cumulative carbon-equivalent $\left(\mathrm{CO}_{2} \mathrm{e}\right)$ emissions are constrained to a total of $1980 \mathrm{GtCO}_{2} \mathrm{e}$ during 2010-2100 (consistent with a 50\% likelihood of global mean temperatures rising no more than $2^{\circ} \mathrm{C}$ above pre-industrial levels). This scenario does not force the model to meet commitments made by particular countries to reduce emissions. Instead, the model is free to determine the least-cost global abatement.

1. Static technological development: Transport technologies undergo no learning; transport technology costs are constant across the model time horizon.

2. ETL base case scenario. Transport technologies undergo ETL; roll-out of hydrogen and electric vehicles occurs only when they become cost effective.

3. ETL Early hydrogen deployment scenarios: Cases in which countries deploy hydrogen vehicles before they are part of a cost-optimal carbon abatement solution. There are several scenario variants:

- Three scenarios examine differing levels of non-optimal early deployment of fuel cell cars, representing efforts made by countries to launch fuel cell vehicles domestically in order to capture first-mover advantages in this technology. The first of these scenarios envisages Germany and Japan each deploying 15,000 vehicles in 2020 . The importance of early deployment is further tested by running scenarios with twice and four times this early deployment level. 
- An additional early deployment scenario examines early deployment of fuel cell buses. This scenario supposes that some cities force uptake of fuel cell buses for air quality reasons.

4. ETL No CCS scenario. Deployment of carbon capture and storage (CCS) technologies is prevented; otherwise same as ETL base case scenario

5. ETL Late action scenario. Global mitigation is delayed; no emissions reductions against the base case are possible before 2020 in this scenario; otherwise same as ETL base case scenario.

The global availability of bioenergy is uncertain, and it may have an important effect on the cost-effectiveness of low-carbon vehicle technologies, since biofuels derived from biomass might be expected to compete with hydrogen and electricity in a low carbon scenario. The base case scenarios assume that global availability of biomass is broadly in line with the more optimistic scenarios of Erb et al. (2009). However, Slade et al. (2001) note that the literature encompasses estimates of significantly greater global biomass availability. Each of the above scenarios has therefore also been tested under more optimistic assumptions about the global availability of biomass, in which the availability of biomass is twice that in the base case.

\section{Results}

\subsection{Roles for hydrogen and electricity in the transport sector}

Static Technology Scenario

Without significant learning, hydrogen and electric vehicles remain too expensive, and hence play a minimal role, appearing only in 2095, in the transport sector even under a stringent carbon constraint.

Endogenous Technology Learning base scenario (ETL)

When the model is allowed to benefit from learning-by-doing, hydrogen and electricity both play a substantial role. Learning brings down the cost of fuel cells and electric vehicle components, enabling hydrogen and electricity to become cost-effective transport fuels.

\section{Early Hydrogen Deployment Scenarios}

The forced eary deployment in these scenarios does not change long-term transport sector hydrogen or electricity consumption patterns as compared to the ETL scenario. While early deployment reduces vehicle costs, these technologies and their associated infrastructure remain too expensive to justify deployment until marginal abatement costs have risen further.

\section{Later Action Scenario}

Combined consumption of electricity and hydrogen in the transport sector substantially exceeds that in the ETL base case scenario. This is because the model is 
unable to reduce emissions before 2020, and must therefore 'work harder' to reduce emissions after this date to remain within the cumulative carbon emissions budget.

\section{No CCS scenario}

This scenario shows a similar pattern to the late action scenario. In the absence of CCS technologies, the model must reduce emissions more quickly in end-use sectors including transport, and so deploys both battery electric vehicles and fuel cells more rapidly than in the ETL base case.

\section{Sensitivity scenarios on Biomass Availability}

In the base case runs, the model deploys bioenergy in the power sector and in industry, often in combination with CCS, rather than in the transport sector. One might imagine that in scenarios with greater availability of bionenergy, the model might select biofuels rather than electricity or hydrogen.

However, the results of the biomass resource sensitivity scenarios do not support this view. Instead, increasing biomass resource availability increases the ability of the model to deploy bio-CCS (which is assumed to be net carbon negative). As a result, the model delays the entry of hydrogen and electricity into the transport sector, with little early deployment of either, as end-use sectors need less decarbonisation thanks to the greater contribution from bio-CCS to emissions reductions.

\subsection{Transport technology deployment pathways}

Within each of the vehicle classes, the results suggest a sequence of vehicle technology transitions. In all vehicle types, the sequence begins with hybridisation of the vehicle fleet, reducing the fuel consumption and deploying a significant number of electric drive-trains and automotive battery systems. Later, these hybrids are replaced, sometimes followed by plug-in hybrid technology as an intermediate stage, and ultimately followed by hydrogen fuel cell technologies, and for cars some battery electric vehicles. An example of this pattern is shown in Figure 3 .

Many studies applying endogenous technology learning find that the model seeks to deploy in early periods a very large amount of the ultimate technology (in this case usually fuel cell vehicles), since early deployment drives down costs and those lower costs can be enjoyed for the rest of the modelling period. However, with components sharing learning, and recombined across different vehicle modes and platforms (and across different global markets in the 16 regions of the model), the model can reduce the costs associated with moving down the learning curve by sequential deployment of technologies that contribute to learning without incurring the high costs associated with an early massive deployment of not-yet costeffective technologies. 


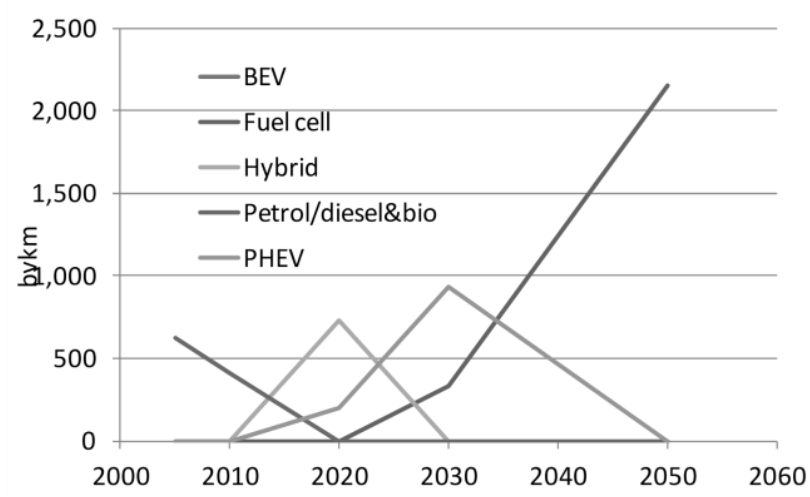

Fig. 3. Sequential deployment of different vehicle technologies (2005-2050) in Light Goods Vehicles (ETL-base case scenario).

There is also a sequence in terms of the timing of deployment of low-carbon technologies across vehicle types. Fuel cells are deployed first in buses and LGVs, which have higher average annual mileage than cars, and which therefore prioritise lower running costs (and hence higher efficiency) more highly than cars. In LGVs, the model first deploys hydrogen, and ultimately transitions to electric vehicles after 2075 in many scenarios. This is likely to be because the efficiency of electric vehicles is higher than that of hydrogen, but so is the capital cost. It is only later in the period, when carbon abatement costs have become very high, that the model prefers the greater efficiency of battery electric vehicles.

The deployment of vehicles results in the deployment of the key technologies that undergo learning. Fuel cell technology becomes cost effective first in buses and LGVs, and then in cars following the cost reductions associated with deployment. Electric drive trains and batteries are cost effective starting in hybrid vehicles, and are subsequently deployed in all other low-carbon vehicle types.

\subsection{Implications of ETL for vehicle cost}

Cumulative investment brings down the costs of key technologies (fuel cell, electric battery and electric drive) in all scenarios in which ETL is applied (ETL base case scenario is shown in Figure 4). Since the learning rate for fuel cells $(18 \%)$ is relatively high compared to that of batteries $(7 \%)$ and electric drive-trains $(10 \%)$, the cost of fuel cells decreases more rapidly. Battery costs fall quickly to just over $\$ 300 / \mathrm{kWh}$, but are not deployed in sufficiently large quantities to reach their potential floor cost of $\$ 150 / \mathrm{kWh}$. The cost of fuel cells in 2050 is reduced to less than a twentieth of the 2015 cost. To achieve these cost reductions, the transport sector requires a cumulative installed capacity of around $131,000 \mathrm{GW}$ of fuel cells by 2050 worldwide; corresponding to a cumulative total of around 1.6 billion vehicles, with around 53 million new fuel cell vehicles added each year by 2050. 


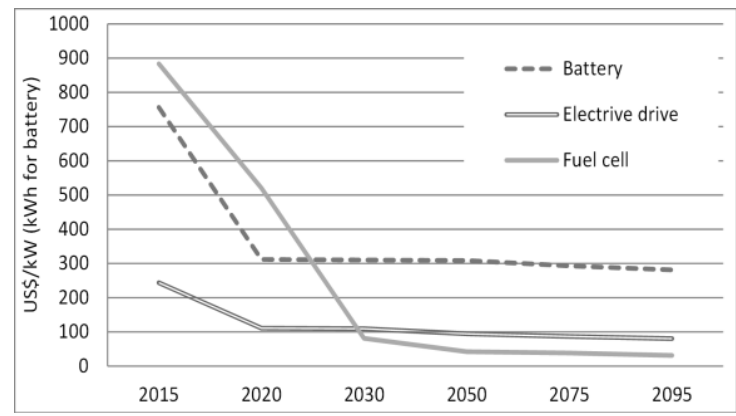

Fig. 4. Unit cost of key technologies in the base case ETL scenario.

The investment (discounted to base year 2005) over the 35 years from 2015 to 2050 that achieves these cost reductions in fuel cells is a cumulative global total of $\$ 1,200$ bn (i.e. the cumulative total investment in fuel cell technologies globally). The figure for the 15 years from 2015 to 2030 is $\$ 64$ billion (required to have a cumulative installed capacity of around $1,860 \mathrm{GW}$ of fuel cell by 2030). However, this cost is offset by the avoided investments in the conventional technology: petrol and diesel engines. As a result, the additional 'learning investments' required to bring down fuel cell cost are rather small, around \$33bn (discounted to base year 2005) for the 15 years.

As noted above, it is larger vehicles with higher annual mileage ${ }^{3}$ that are deployed first, rather than cars. Nevertheless, the costs of fuel cell cars is reduced significantly in 2030 (Figure 5), despite having had no deployment of fuel cells in cars by that date. Instead, roll-out of fuel cell buses and light-goods vehicles has driven down the costs of fuel cells and other EV components, reducing the capital costs of fuel cell vehicles. Even so, fuel cell vehicles remain too expensive in the near term to compete with conventional hybrids, which are deployed globally resulting in a significant reduction in global transport $\mathrm{CO}_{2}$ emissions. Only from 2050 onwards, as emissions constraints bite further, does the transition to hydrogen passenger mobility begin.

The early deployment scenarios demonstrate a clear effect on near term costs, with early deployment of fuel cell technologies in cars or buses driving down costs of key components. This is shown in Figure 5. However, despite these accelerated cost reductions in the near term, the early deployment scenarios do not have a sufficiently large impact on costs to accelerate adoption. Given the presence of other, cheaper abatement opportunities throughout the energy system, the model prefers to deploy hydrogen vehicles later, as carbon abatement costs rise.

\footnotetext{
${ }^{3}$ Average annual mileages for buses and light goods vehicles are much higher than for cars. In the model, this is reflected in assumed average annual mileages specific to each vehicle mode.
} 


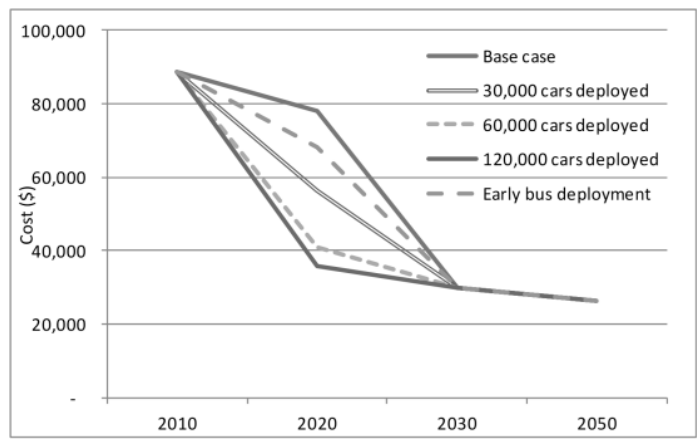

Fig. 5. Capital cost of a hybrid fuel cell vehicle under different early deployment scenarios.

\subsection{Hydrogen versus Electric Vehicles?}

There is an on-going debate about the complementarity or competitiveness of hydrogen and electric vehicles (Bento 2010). In the results presented here, both hydrogen fuel cell vehicles and battery electric vehicles are deployed in all scenarios. At a global level then, the model does not support an absolute trade-off between hydrogen and electricity as transport fuels, since different markets in different regions may prefer one or the other ${ }^{4}$, and both are required to achieve global decarbonisation at least cost. There is also significant deployment of fuel cell plug-in hybrid electric vehicles (FCPHEVs) in all scenarios, representing a complementarity between fuel cell and battery electric technology at the level of the individual vehicle.

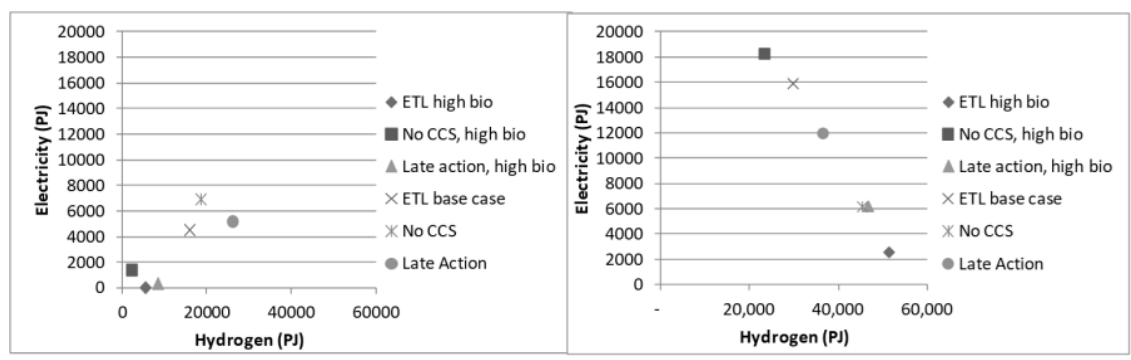

Fig. 6. Transport sector consumption of hydrogen and electricity under different scenarios, in 2050 (left panel) and 2095 (right panel).

In the medium term, therefore, there appears to be synergy between vehicles using hydrogen and electricity as fuels, as scenarios with more hydrogen vehicles (FCVs and FCHVs) tend also to deploy more electric vehicles (BEVs, Petrol and diesel PHEVs), in part because of the shared cost reductions. By the end of the

\footnotetext{
${ }^{4}$ Technology costs are global, but fuel production costs and carbon intensities vary, reflecting different resource endowments, and this can result in different fuels being preferred in different regions.
} 
century, most passenger cars and light goods vehicles are fuelled with either hydrogen or electricity or both (FC PHEVs). In this heavily decarbonised transport sector, hydrogen and electricity become competitors in the sense that scenarios with more of one have less of the other (see Figure 6). It should be noted from the axes of the diagram that in the long term (by 2095), more hydrogen than electricity is consumed by the transport sector in all scenarios.

\section{Conclusions, limitations and policy implications}

The study concludes that electricity and hydrogen emerge as complementary fuels, rather than as strict competitors, with both deployed in all scenarios. This reflects the fact that hydrogen and battery electric vehicles share components: in the near term, deployment of hybrid cars reduces the costs of components that are used in fuel cell vehicles; and later deployments of fuel cell vehicles further reduce the costs of battery electric vehicle components, resulting in synergy rather than competition between hydrogen and electricity technologies. However, in the long term when the transport sector has been largely decarbonised, technology competition between hydrogen and electricity does arise, in the sense that scenarios using more electricity in the transport sector use less hydrogen and vice versa.

Methodologically, a key observation is that a multi-cluster approach appears to overcome a shortcoming found by many previous authors. Specifically, while many previous applications of ETL within MARKAL/TIMES models have observed either immediate and rapid or zero deployment of the learning technology, with a resulting need for transition rate constraints, the multi-cluster approach presented here results in a gradual and phased deployment of the learning technology. The multi-cluster approach thus appears to be a promising approach to improving the modelling of endogenous technological change.

However, there are limitations that should be borne in mind in considering the conclusions from a policy perspective. In particular, there is deep uncertainty relating to the learning curve specifications, including the value of the learning rate and potential changes to the learning rate over time. Moreover, real world multiple and divergent scale-dependent drivers of cost reduction have been modelled with a single factor. Similarly, a single global learning process has been modelled here, whereas in reality some components of learning tend to be location specific (e.g. related to local practices and institutions). These uncertainties and limitations are in addition to those inherent in all long-term energy system optimization, and the results are not intended to be predictive, but rather are intended to yield insights into possible dynamics and patterns in the energy system.

The messages for policymakers must therefore be drawn with caution. The current analysis suggests that, in the long-term, both hydrogen and electricity remain important options for long-term decarbonisation. The results also suggest that pol- 
icymakers seeking to accelerate the deployment of hydrogen or electric vehicles through early deployments may be disappointed if the rest-of-the-world follows a least-cost abatement trajectory.

\section{Acknowledgement}

TIAM-UCL was developed through the UK Energy Research Centre, while the analysis reported in this chapter was part of the UK Sustainable Hydrogen Energy Consortium. The RCUK Energy Programme funded both these initiatives.

\section{References}

Anandarajah, G., McDowall, W., \& Ekins, P. (2013). Decarbonising road transport with hydrogen and electricity: Long term global technology learning scenarios. International Journal of Hydrogen Energy, 38(8), 3419-3432.

Bento, N (2010) Dynamic competition between plug-in hybrid and hydrogen fuel cell vehicles for personal transportation, Int J Hydrogen Energ, 35(20): 11271-11283.

Bergek A, Jacobsson S, Carlsson B et al (2008) Analyzing the functional dynamics of technological innovation systems: A scheme of analysis. Research policy 37: 407-429.

Criqui P, Mima S, Menanteau P et al (2014)Mitigation strategies and technology learning: An assessment with the POLES model, Technology Forecasting and social Science, article in press.

Eames 2000 The Large Combustion Plant Directive (88/609/EEC): An Effective Instrument For Pollution Abatement? University of Sussex

Erb KH, Haberi H, Krausmann F et al (2009) Eating the planet: Feeding and fuelling the world sustainably, fairly and humanely - a scoping study (Commissioned by Compassion in World Farming and Friends of the Earth UK). Institute of Social Ecology and PIK Potsdam, Vienna, Potsdam.

de Feber MAPC, Schaeffer GL, Seebregts AJ et al (2003) Enhancements of endogenous technology learning in the western European MARKAL model. Report for the EU SAPIENT project, ECN, Petten.

Gritsevskyi A, Nakićenovic N (2000) Modeling uncertainty of induced technological change. Energy Policy 28: 907-921.

Grubb M, Köhler J, Anderson D (2002). Induced Technical Change in Energy and Environmental Modelling: Analytic Approaches and Policy Implications. Annual Review of Energy and the Environment 27: 271-308.

Grübler A, Nakicenovic N, Victor D (1999) Dynamics of Energy Technologies and Global Change, Energy Policy, 27: 247-280.

Gül T, Kypreos S, Turton H et al (2009). An energy-economic scenario analysis of alternative fuels for personal transport using the global multi-regional markal model (GMM). Energy 34: no. 10: 1423-37.

Kahouli-Brahmi S (2008) Technological learning in energy-environment-economy modelling: A survey, Energy Policy 36: 138-162.

Krzyzanowski D, Kypreos S, Barreto L (2008) Supporting hydrogen based transportation: Case studies with global markal model. Computational Management Science 5, no. 3: 207-31.

Krzyzanowski D, Kypreos S, Grutzwiller L, et al (2004) Implications of Technology Learning in Energy-Economy Models of the Transport Sector. Report to the Alliance for the Global Sustainability (AGS). Paul Scherrer Institute, Switzerland. 
Mattsson N, Wene CO (1997) Assessing new energy technologies using an energy system model with endogenized experience curves. Int J Energ Res 21(4): 385-93.

McDonald A, Schrattenholzer L (2001) Learning rates for energy technologies. Energy Policy 29: 255-261.

McDowall (2012) Endogenous technology learning for hydrogen and fuel cell technology in UKSHEC II: Literature review, research questions and data. UKSHEC Social Science Working Paper 8. UCL Energy Institute.

McDowall W, Dodds P (2012) A review of low-carbon vehicle and hydrogen end-use data for energy system models. UKSHEC Working Paper 5. UCL Energy Institute.

Lipman T, Hwang R (2003) Hybrid Electric And Fuel Cell Vehicle Technological Innovation: Hybrid and Zero-Emission Vehicle Technology Links. 20th International Electric Vehicle Symposium and Exposition, November 15-19, Long Beach, California.

Loulou R, Remme U, Kanudia A et al (2005) Documentation of the TIMES model: Part II. Energy Technology System Analysis Programme.

Loulou R, Labriet M (2007) ETSAP-TIAM: the TIMES integrated assessment model Part I: Model structure (2007), DOI 10.1007/s10287-007-0046-z.

Rout UK, Blesl M, Fahl U et al (2009) Uncertainty in Learning Rates of the Energy Technologies: An Experiment in a Global Multi-Regional Energy System Model. Energy Policy 37 (11): 4927-4942.

Seebregts AJ, Kram T, Schaeffer GJ et al (1998) Endogenous technology learning: experiments with MARKAL, Contribution to Task 2.3 of the EU-TEEM Project. ECN, Petten.

Seebregts A, Kram T, Schaeffer GJ et al (1999) Endogenous technological change in energy system models: synthesis of experience with ERIS, MARKAL and MESSAGE. ECN-C--99-025, PSI, IIASA, Laxenburg, Austria.

Slade R, Saunders R, Gross R et al (2011). Energy from biomass: the size of the global resource. UKERC Report number: UKERC/RR/TPA/2011/001. UK Energy Research Centre, London.

Totschnig G, and Keppo I (2007) CASCADE-MINTS Part 1: an analysis with MESSAGE. Final Report to the Energy - Economics - Environment Modeling Laboratory(E3MLAB) at the Institute of Communication and Computer Systems of the National Technical University of Athens, Athens, Greece.

Watanabe C, Wakabayashi K, Miyazawa T (2000) Industrial dynamism and the creation of a "virtuous cycle" between R\&D, market growth and price reduction: The case of photovoltaic power generation (PV) development in Japan. Technovation 20: 299-312.

Winskel M, Markusson N, Jeffrey H., 2014, Learning pathways for energy supply technologies: Bridging between innovation studies and learning rates, Technological Forecasting and Social Change, Vol81: ISSN:0040-1625, Pages: 96-114

Winskel M, Markusson N, Jeffrey H et al (2013) Between Learning Rates and Innovation Studies: Learning Pathways for Emerging Energy Supply Technologies', Technological Forecasting and Social Change, 81, 96-114

Yeh S, Rubin E (2012) A review of uncertainties in technology experience curves, Energy Economics 34 (3): 762-771

Zaetta R, Madden B (2011) Hydrogen fuel cell bus technology state of the art review. Element Energy report for the NextHyLights project. Cambridge. 